\section{Comprometimento Organizacional da Mão-de-Obra na Hotelaria de Uberlândia}

Hespitality Labour Organization Commitment in Uberlandia

\section{Évora Mandim Ribeiro Naves' Marilia Ferreira Dela Coleta ${ }^{2}$}

\begin{abstract}
RESUMO: Pesquisa de campo que analisa o nível de comprometimento dos funcionários de algumas empresas hoteleiras da cidade de Uberlândia. $\mathrm{Na}$ investigação utilizou-se o modelo teórico das três dimensões de Meyer Allen \& Smith (1993) (comprometimento normativo, instrumental e afetivo), adaptado no Brasil por Medeiros (1997). Utiliza-se de estatísticas descritivas, testes de hipóteses, análise de correlações e análise de variância para análise dos dados. Os resultados demonstram que, apesar de os sujeitos terem se mostrado comprometidos com as organizações, prevalece na amostra o vínculo normativo. As médias das dimensões do comprometimento, no caso da população pesquisada, são afetadas pelas características biográficas, e apresentaram correlações com as variáveis profissionais.
\end{abstract}

PALAVRAS-CHAVE: hotelaria; empresas hoteleiras; hotéis; comprometimento organizacional; perfil da mão-de-obra; Uberlândia; Minas Gerais; Brasil.

ABSTRACT: It is a field research that analyses the level of organizational commitment in some hospitality industry on Uberlândia. In the investigation it was used a theoretical model based on the studies of the three dimensions

\footnotetext{
1. Bacharel em Administração pela Universidade Federal de Uberlândia (UFU). Especialista em Gestão Empresarial pela UFU. Mestre em Administração. Docente das disciplinas Administração de Recursos Humanos e Comportamento Organizacional dos cursos de Turismo e Administração do Centro Universitário do Triângulo (Unit).E-mail: evora@rapidanet.com.br.

2. Doutora em Psicologia Social pela Universidade de Brasília. Docente da Faculdade de Psicologia - Universidade Federal de Uberlândia. E-mail: mariliacoleta@enetec.com.br.
}

of Meyer, Allen \& Smith (1993) (normative, continuance and affective commitment), adapted in Brazil by Medeiros (1997). Besides descriptive statistics, tests of difference of averages, analysis of correlations and multiple regression, appear on the study. The results demonstrate that the research subjects, in spite of showing committed to the organizations, it prevails in the sample the normative entail.Stands out, still, the existence of relationships between the types of organizational commitment and biography characteristic and professionals variables.

KEYWORDS: hospitality industry; hotel sector companies; hotels; organizational commitment; labor profile; Uberlândia; Minas Gerais; Brazil.

\section{Introdução}

O turismo é hoje um campo de investimento que vem ganhando uma importância cada vez maior no contexto do desenvolvimento socioeconômico. Basta ver que algumas cidades, que há poucos anos não figuravam no mapa nacional do turismo, hoje se constituem em fortes centros receptores, impulsionando, desta forma, sua arrancada para o desenvolvimento. Dentro deste contexto, a indústria hoteleira não pode ser considerada uma atividade marginal, mas sim um elemento estratégico para uma política de desenvolvimento turístico de uma região.

O diferencial da empresa hoteleira está nos serviços, considerando que a estrutura física, o conforto, as amenidades (bombons, boa-noite, xampu, secador de cabelo no banheiro, etc.) são prontamente copiados pelos concorrentes. A esse respeito, Brown (1992) define que existe uma regra de ouro para a excelência dos serviços: faça com seus clientes internos como você deveria fazer com seus clientes externos. Em outras palavras, o serviço excepcional não pode ser prestado aos hóspedes antes de bons serviços existirem no âmago da organização.

O dinamarquês Moller (1997) acredita estar na qualidade subjetiva a sobrevivência de uma empresa de serviços. Em seu entender, a qualidade subjetiva se expressa diretamente pelo provedor do serviço, e pode ser representada pela atitude, pelo comprometimento, pela flexibilidade, pela rapidez e, o mais importante, pela atenção demonstrada ao cliente.

Fica claro a importância da hospitalidade para o setor hoteleiro. Desta forma, as empresas devem promover uma cultura organizacional que motive os seus clientes internos à busca do comprometimento, à profissionalização e à satisfação dos clientes externos incessantemente. 
A arquiteta Ana Maria Wey $(\mathrm{ABIH}, 2002)$ faz considerações aos hotéis do futuro, devendo ser mais sensíveis que técnicos:

- o hóspede deve sentir-se em casa, porém com todos os atrativos de algo novo, inesperado, moderno;

- charme e elegância serão os substitutos para o luxo;

- os serviços deverão ser perfeitos e pessoais;

- o hotel deverá ser um grande anfitrião. Receberá seus hóspedes, como convidados, da melhor maneira possível, com sutilezas e agrados para que saiam muito satisfeitos;

- os empregados deverão estar preparados para atender os hóspedes até em pequenos serviços, como fazer uma bainha de calça ou pregar botões, ou até ir buscar uma encomenda, entre outros.

Assim, fica evidente para as empresas hoteleiras a importância de se ter profissionais comprometidos com a organização. Dentro deste panorama, tornase importante para os hotéis saber qual o nível do comprometimento presente. $\mathrm{O}$ comprometimento organizacional, em termos gerais, pode ser entendido como o envolvimento com a organização que incita a realizar um esforço considerável em prol da empresa.

Este trabalho, em primeiro lugar, realiza uma reflexão conceitual sobre o construto comprometimento organizacional, abordando conceito, principais enfoques e o modelo das três dimensões de Meyer \& Allen (1991), objeto de estudo. Posteriormente apresentam-se os resultados da pesquisa realizada nos hotéis na cidade de Uberlândia e, finalmente, são feitas algumas considerações que podem servir de indicações para futuras pesquisas.

\section{Comprometimento Organizacional}

O tema comprometimento organizacional tem sido objeto de estudo de vários pesquisadores nas últimas décadas, objetivando auxiliar as organizações a encontrarem estratégias de gerenciamento de seu pessoal que os tornem mais satisfeitos, mais envolvidos com a empresa e, por conseguinte, mais produtivos.

Comprometimento é estudado em função dos focos ou alvos e das bases ou natureza do vínculo. São inúmeros os alvos de vínculo que o trabalhador tem com a organização (grupo, sindicato, valores, profissão, trabalho, etc.), assim como são inúmeras as naturezas destes vínculos (afetiva, instrumental, normativa, etc.).
Vale ressaltar ainda que, dentro de cada foco (alvo), especialmente com a organização e o sindicato, existem abordagens diferenciadas quanto às bases (naturezas).

São cinco as correntes de pesquisa sobre comprometimento: afetivoatitudinal, instrumental (contínua ou side-bet), normativa, sociológica e comportamental. Embora existam várias vertentes que abordem o construto comprometimento organizacional, elas compartilham da premissa de que o vínculo existe e é inevitável, significando: o desejo de permanecer na organização, de exercer suas atividades, de acreditar e aceitar os objetivos e valores organizacionais.

\section{Enfoque afetivo-atitudinal}

A linha de pesquisa que considera a natureza do vínculo como afetivo/ atitudinal prevalece entre os pesquisadores. Suas bases se fundamentam nas teorias de Etzioni (1975), sendo esta abordagem mais tarde aprimorada com os trabalhos de Mowday, Steers e Porter (1979). Para os autores, estar comprometido com a organização significa a identificação e o envolvimento com a organização. $\mathrm{O}$ indivíduo comprometido realiza um esforço considerável em prol da organização.

Assim, eles o caracterizam como: a) uma forte crença e aceitação dos objetivos e valores da organização; b) uma tendência a manifestar um esforço considerável em favor da organização; c) a manifestação de um forte desejo de permanecer como membro da organização.

A partir desta definição, verifica-se que indivíduos com elevado grau de comprometimento demonstram uma internalização dos valores e objetivos da organização e, por conseguinte, tendem a exercer um esforço considerável em favor dela. Sob esse ponto de vista, o indivíduo assume uma postura ativa. Estão dispostos a se empenhar ao máximo, contribuindo de forma positiva para a empresa.

\section{Enfoque instrumental}

O enfoque instrumental constitui o segundo grande referencial teórico adotado nas pesquisas sobre o tema, cujas denominações são: calculativo, continuação, side-bets (BASTOS, 1994). Esta corrente originou-se nos trabalhos de Becker (1960), traduzindo-o como função da percepção do trabalhador quanto às trocas estabelecidas com a organização. Segundo o autor, o indivíduo permanece na organização devido a custos e benefícios associados à sua saída. Em outras palavras, o empregado irá optar por permanecer na empresa enquanto perceber benefícios 
nessa escolha. No momento em que perceber um déficit em relação aos retornos recebidos, sua escolha provavelmente será abandonar a empresa.

O comprometimento instrumental foi operacionalizado pelas escalas desenvolvidas num primeiro momento por Ritzer e Trice (1969) e, posteriormente, por Hrebiniak e Alluto (1972).

\section{Enfoque normativo}

A corrente de pesquisa normativa é ancorada nos trabalhos de Wiener (1982) e Wiener e Vardi (1990), influenciada pelas contribuições de Etzioni (1975). Segundo a corrente normativa, o comprometimento é visto como o conjunto de pressões normativas internalizadas para que o indivíduo se comporte de acordo com os objetivos e metas da organização. O enfoque normativo procura trabalhar o plano organizacional por meio da análise da cultura e o lado individual, por meio dos processos motivacionais. Parte do pressuposto de que o comportamento do indivíduo é conduzido de acordo com o conjunto de normas que ele assume internamente.

Wiener e Vardi (1990) defendem que a cultura organizacional é capaz de atuar junto aos empregados com o intuito de envolvê-los nos ideais da organização, permanecendo esta influência estável no corpo dos funcionários. É importante destacar que esta adesão vai depender dos valores e normas partilhados e do que os membros acreditam ser a conduta ética e moral.

Uma terceira corrente que merece destaque e ampara os estudos desta pesquisa é o enfoque das três dimensões de Meyer e Allen.

\section{0 enfoque das três dimensões de Meyer \& Allen}

A conceitualização do comprometimento organizacional em três dimensões - afetivo, instrumental e normativo - foi decorrente da análise de variância (Anova) realizada por Meyer e Allen. Nesta análise concluíram que as escalas propostas por Ritzer-Trice e Hrebiniak-Alluto não mediam o comprometimento instrumental, conceitualizado por Becker, pois apresentava uma maior correlação com o componente afetivo. Com isso desenvolveram dois questionários, um para medir o comprometimento afetivo, Affective Commitmente Scale (ACS) e outro para medir o comprometimento instrumental, Continuance Commitment Scale (CCS).

Mais tarde, McGee e Ford (1987), aplicando as escalas desenvolvidas por Meyer e Allen e utilizando-se da análise fatorial, verificaram o surgimento de uma nova dimensão do comprometimento, denominada normativa, composta de itens que refletiam o sacrifício pessoal do empregado na hipótese de deixar a organização.

A conceitualização da dimensão normativa está apoiada no trabalho de Wiener (1982). Posteriormente, Meyer e Allen (1991) incorporaram à nova dimensão e conceitualizaram o comprometimento organizacional em função das três dimensões:

- comprometimento como um apego afetivo com a organização;

- comprometimento percebido em função dos custos associados de deixar a organização;

- comprometimento como uma obrigação de permanecer na organização.

Meyer e Allen (1991: 3) caracterizam os três tipos de vínculos entre indivíduos e organização da seguinte forma:

Empregados com um forte comprometimento afetivo permanecem na organização porque eles querem, aqueles com comprometimento instrumental permanecem porque eles precisam e aqueles com comprometimento normativo permanecem porque eles sentem que são obrigados.

Segundo os autores, estes três tipos de bases estariam presentes no vínculo indivíduo-organização, porém com intensidades diferenciadas.

Esta abordagem múltipla está presente nas agendas dos pesquisadores, tanto brasileiros (MEDEIROS, 1997; BANDEIRA, 1999; BASTOS, 1999) como estrangeiros (CLUGSTON, 2000).

\section{Algumas considerações sobre o nível do comprometimento}

Randall (1987: 466-467), em seu artigo Commitment and the Organization: the organization man revisited, faz menção às conseqüências positivas e negativas dos vários níveis de comprometimento, tanto para os empregados como para as organizações. Segundo ele:

(...) os níveis moderados de comprometimento apresentam maiores vantagens do que desvantagens, tanto para a empresa como para os funcionários.

A mão-de-obra é mais estável e satisfeita, sem ser consumida pela organização.

Os indivíduos são capazes de ajustar-se às colocaçōes de comportamento, 
pela variação de seus graus de comprometimento de acordo com a atratividade percebida. A relação entre as necessidades do individuo e as necessidades organizacionais podem ser equilibradas. Níveis mais altos de comprometimento são mais custosos que as vantagens apresentadas para a organização, pois os indivíduos podem perder a flexibilidade, além do excesso de zelo poder implicar em comportamentos antiéticos e ilegais.

Verifica-se que algum grau de comprometimento organizacional pelos empregados é necessário para as organizações funcionarem efetivamente dentro da sociedade, devendo haver a presença da dimensão afetiva dentro do rol das outras duas dimensões do comprometimento. Contudo, a relação entre comprometimento e as suas conseqüências não deve obedecer a uma curva linear. A melhor curva entre estas variáveis seria em forma de U invertida, com um ápice em um nível moderado de compromisso, permitindo o equilíbrio entre as necessida des individuais e organizacionais, dentro de níveis moderados de engajamento.

\section{Gerenciando o comprometimento}

Os resultados das pesquisas indicam que as práticas de recursos humanos podem influenciar o comprometimento dos empregados. Sabe-se que os empregados reagem às condições conforme eles as percebem. Assim, é mais provável que eles respondam a uma política ou prática no sentido desejado (aumento de comprometimento) se acreditarem que a organização é responsável pela introdução e consideração dos seus interesses (MEYER; ALLEN, 1997).

Koys, citado por Meyer e Allen (1997), encontrou que as práticas de recursos humanos eram mais prováveis de influenciar o compromisso dos empregados quando foram vistas como motivadas por um interesse para os empregados, em vez de satisfazer uma exigência legal da empresa ou um desejo de aumentar a produtividade.

Os achados ilustram a importância de uma comunicação no projeto e na execução de práticas de recursos humanos. Esta comunicação deve incluir esforços para informar empregados sobre a finalidade pretendida das práticas e solicitar o feedback dos empregados sobre a percepção e reação às práticas de recursos humanos. Assim, as práticas de recursos humanos devem ser conduzidas conforme a percepção dos empregados para proporcionar um desenvolvimento maior das dimensões afetivas e normativas do comprometimento, obedecendo às considerações expostas por Randall (1987).

\section{Hotéis de Uberlândia - Dimensões do Comprometimento Organizacional}

\section{Metodologia}

Trata-se de uma pesquisa de campo que procura identificar o nível das dimensões do comprometimento presente em alguns hotéis convencionais da cidade de Uberlândia. A escolha dos hotéis foi intencional, cujos critérios foram: ser classificados como muito confortável e de médio conforto, pela classificação do Guia Quatro Rodas, e que tivessem mais de 100 UH's. Um total de 223 pessoas foi pesquisado de um universo de 251 funcionários. Participaram da pesquisa todos os funcionários registrados em carteira e que possuíam escolaridade de, no mínimo, ensino fundamental incompleto.

A variável Comprometimento Organizacional foi operacionalizada segundo a teoria das três dimensões de Meyer, Allen \& Smith (1993), a partir do instrumento validado por Medeiros (1997) no Brasil. Trata-se de uma escala multifatorial com 18 afirmações, sendo os seis primeiros indicadores de Comprometimento Afetivo, os seis seguintes indicadores de Comprometimento Instrumental e os seis últimos indicadores de Comprometimento Normativo. Para esta escala foi utilizado o formato Likert com cinco níveis de resposta. Além do nível de comprometimento, foram levantadas também algumas características relacionadas ao perfil da mão-de-obra, utilizando as seguintes variáveis: idade, sexo, estado civil, salário, avaliação dos treinamentos oferecidos como oportunidade de desenvolvimento, expectativa atendida nos primeiros meses de trabalho, socialização, atividade mais importante na vida e exercício de outra atividade fora do horário de trabalho.

A estratégia de tratamento dos dados consistiu em análise quantitativa, sendo conduzida por meio de processo multivariado de tratamento dos dados. Esses foram analisados com o auxílio do pacote estatístico SPSS, versão 8.0 para Windows. O índice de correlação de Pearson foi utilizado para verificar a correlação das variáveis biográficas-profissionais com o construto estudado. A análise de variância permitiu identificar as diferenças entre os grupos. E finalmente a estatística descritiva auxiliou na caracterização completa da amostra.

\section{Análise e discussão dos resultados}

O trabalho realizado consistiu, fundamentalmente, em responder qual o nível das dimensões do comprometimento organizacional presentes nos princi- 
pais hotéis de Uberlândia e qual a relação entre as características biográficas e profissionais com o construto.

Para o alcance desses objetivos, primeiramente faz-se uma descrição do perfil dos sujeitos pesquisados, a seguir é analisado o nível de comprometimento da amostra, sendo realizada uma comparação entre os hotéis. Em seguida relacionam-se as variáveis características biográficas e pessoais e as três dimensōes do comprometimento.

\section{0 perfil dos sujeitos}

Do total de 251 funcionários efetivos que trabalham nos hotéis pesquisados, 223 funcionários responderam ao questionário, o que equivale a $88,8 \%$ da população. Desse total, sete questionários não puderam ser aproveitados por apresentar mais de 11 questōes em branco, relativos a $24 \%$ dos construtos mensurados. Após a eliminação dos questionários não válidos, a amostra final ficou constituída de 216 respondentes, o que indica, em termos globais, uma taxa de aproveitamento de $86 \%$, considerada bastante satisfatória.

Nos hotéis pesquisados há um predomínio de pessoas do sexo masculino e casadas, sendo de 31,4 anos a média de idade. É bom evidenciar que 70,3\% da amostra possui até 35 anos, demonstrando o predomínio de jovens no setor.

Entre as atividades mencionadas como as mais importantes na vida, $60,6 \%$ dos funcionários atribuíram à família, $29,8 \%$ ao trabalho e apenas $3 \%$ aos estudos. Essa distribuição percentual vem corroborar com a baixa escolaridade presente nas empresas pesquisadas, haja vista que apenas $2 \%$ dos pesquisados possuem nível superior completo e 9,5\% superior incompleto. Estes resultados mostram a recentidade do setor na cidade em termos de profissionalização. Vale mencionar que na região existem apenas duas faculdades que ministram curso de Turismo e Hotelaria e que estão operando no mercado há cinco anos.

Aliado à baixa escolaridade, tem-se a falta de experiência no ramo, pois $67 \%$ dos pesquisados nunca trabalharam em empresas do setor de hotelaria, comprovando a necessidade das empresas de formar sua própria mão-de-obra. Este número comprova o percentual de pesquisados, $86 \%$, que passaram por um processo formal de socialização e $51 \%$ participaram de mais de cinco cursos ou treinamentos ao longo dos anos na empresa. Tais resultados parecem colaborar com a variável atendimento das expectativas nos primeiros meses de trabalho, pois $67,3 \%$ dos pesquisados tiveram suas expectativas bastante atendidas.

Em relação ao salário, os resultados demonstram que $87 \%$ dos pesquisados ganham menos de cinco salários mínimos. Este valor deve-se à predominância de cargos operacionais, como camareiras e auxiliares de limpeza no setor. Mesmo com os baixos salários, apenas $12,5 \%$ dos pesquisados exercem outras atividades remuneradas para complementar o orçamento, um percentual muito baixo, tendo em vista os tipos de atividades do setor.

Quanto ao número de promoções recebidas, 53\% dos pesquisados não receberam nenhuma promoção durante o tempo de serviço na empresa, talvez pela ausência de uma administração de recursos humanos na maioria das empresas pesquisadas. Com relação ao tempo de empresa, $25 \%$ dos pesquisados possuem menos de um ano de empresa, $35 \%$ dos pesquisados possuem de um a três anos, $27 \%$ dos pesquisados possuem de três a seis anos de empresa.

\section{Nível de comprometimento}

A seguir verificou-se o nível de comprometimento da amostra. Os resultados do Gráfico 1 mostram a presença das três dimensões do comprometimento, em nível moderado, entre os sujeitos pesquisados. Merece destaque a dimensão normativa na amostra, com média 3,93 . Tal predominância confirma o engajamento dos funcionários estabelecido em função das normas e das regras existentes no setor para assegurar a padronização dos serviços oferecidos.

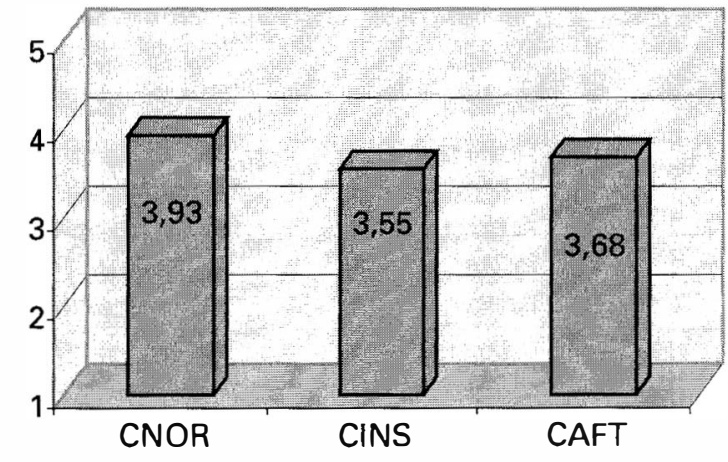

Figura 1 Distribuição das médias das três dimensões do comprometimento na amostra.

Fonte: Dados da pesquisa.

Quanto ao nível de comprometimento organizacional presente nas empresas, primeiramente descreve-se o perfil dos hotéis pesquisados, para que então se possa compará-los em relação ao nível de comprometimento apresentado. 
O hotel A é um hotel tradicional, de gestão familiar, apresentando apenas uma estrutura de departamento pessoal. Está classificado como médio conforto pela classificação do Guia Quatro Rodas e localiza-se na região central da cidade, oferecendo 133 UH's e com 48 funcionários. O hotel B, também de origem familiar, porém, com experiência no ramo hoteleiro, apresenta também apenas uma estrutura de departamento pessoal. Está classificado no Guia Quatro Rodas como médio conforto e localiza-se na região central da cidade, apresentando 120 UH's e 36 funcionários. O hotel C é um hotel residência, administrado por uma grande rede internacional de hotéis, que se caracteriza por apresentar uma gestão de recursos humanos profissional, centralizada na matriz. Já foi condecorado como a melhor empresa para se trabalhar segundo o Guia Exame. Está classificado pelo Guia Quatro Rodas como médio conforto e localiza-se na região central da cidade, apresentando 120 UH's e 35 funcionários. O hotel D pertence a um grande grupo de empresas da cidade e apresenta apenas uma estrutura de departamento pessoal. Está classificado como muito confortável pelo Guia Quatro Rodas e localiza-se na região administrativa da cidade. Oferece 152 UH's e 132 funcionários. Os hotéis descritos acima representam os principais hotéis da cidade.

A Tabela 1 ilustra o resultado da análise descritiva das dimensões e o nível das dimensões do comprometimento organizacional por empresa.

Tabela 1 Análise descritiva do comprometimento organizacional por empresa.

\begin{tabular}{|l|c|c|c|c|}
\hline & Hotel A & Hotel B & Hotel C & Hotel D \\
\hline CNOR & 3,84 & 3,91 & 3,98 & 3,95 \\
\hline CINS & 3,79 & 3,50 & 3,63 & 3,46 \\
\hline CAFT & 3,42 & 3,60 & 3,28 & 3,89 \\
\hline № func. & 40 & 25 & 30 & 121 \\
\hline
\end{tabular}

Fonte: Dados da pesquisa.

Observa-se que todos os valores médios encontram-se entre 3 (ponto médio da escala) e 4 (concordo pouco), indicando a existência dos três vínculos nos hotéis pesquisados. Embora os resultados apontem diferenças nas médias entre os hotéis em relação aos tipos de comprometimento organizacional, faz-se necessário testar o nível de significância destas diferenças. Para isso, utilizou-se a análise de variância - One Way Anova, teste de hipótese utilizado para verificar a diferença entre médias, adequado para comparar mais de dois grupos. Os resultados da análise de variância estão ilustrados na Tabela 2.
Tabela 2 Anova - Comparação das médias dos comprometimentos entre os hotéis pesquisados.

\begin{tabular}{|c|c|c|c|c|c|c|}
\hline & & $\begin{array}{c}\text { Somatória } \\
\text { dos quadrados } \\
\text { SS }\end{array}$ & GI & $\begin{array}{l}\text { Média ao } \\
\text { quadrado } \\
\text { MS }\end{array}$ & $F$ & Sig \\
\hline CNOR & $\begin{array}{l}\text { Entre grupos } \\
\text { Dentro dos grupos } \\
\text { Total }\end{array}$ & $\begin{array}{r}0,45 \\
116,68 \\
117,13 \\
\end{array}$ & $\begin{array}{r}3 \\
212 \\
215 \\
\end{array}$ & $\begin{array}{l}0,15 \\
0,55\end{array}$ & 0,27 & 0,84 \\
\hline CINS & $\begin{array}{l}\text { Entre grupos } \\
\text { Dentro dos grupos } \\
\text { Total }\end{array}$ & $\begin{array}{r}3,55 \\
194,94 \\
198,50\end{array}$ & $\begin{array}{r}3 \\
212 \\
215\end{array}$ & $\begin{array}{l}1,18 \\
0,92\end{array}$ & 1,29 & 0,28 \\
\hline CAFT & $\begin{array}{l}\text { Entre grupos } \\
\text { Dentro dos grupos } \\
\text { Total }\end{array}$ & $\begin{array}{r}12,97 \\
277,19 \\
290,17\end{array}$ & $\begin{array}{r}3 \\
212 \\
215\end{array}$ & $\begin{array}{l}4,32 \\
1,30\end{array}$ & 3,31 & $0,02 *$ \\
\hline
\end{tabular}

Fonte: Dados da pesquisa.

Verifica-se que as médias das dimensões normativa e instrumental do comprometimento entre os hotéis são iguais. Apenas na dimensão afetiva - CAFT apresentou-se diferença entre os hotéis pesquisados. A Anova não permite localizar entre quais deles se encontra esta diferença; deste modo foi efetuado o teste de Tukey, para localizar a diferença entre os grupos, e pôde-se constatar que a diferença entre as médias dos hotéis no comprometimento afetivo - CAFT encontrase apenas do hotel D para o hotel C, pois a significância apresentada de 0,045 é menor que $\mathrm{p}<0,05$. Logo, conclui-se que todas as empresas apresentaram o mesmo nível de comprometimento em relação às dimensões normativa e instrumental. O nível da dimensão afetiva apresentou diferença apenas do hotel $\mathrm{D}(\mathrm{M}=3,89)$ para o hotel $\mathrm{C}(\mathrm{M}=3,28)$.

Com relação às variáveis pessoais/profissionais, as médias por hotel estão especificadas na Tabela 3.

Embora os resultados da Tabela 3 mostrem diferenças entre os hotéis em relação às variáveis pessoais/profissionais, é importante testar se estas diferenças devem-se ao erro amostral ou são características dos sujeitos. Para isso realizouse a Anova. Os resultados estão descritos na Tabela 4.

Os resultados da Tabela 4 mostram existir diferenças entre os hotéis apenas para as variáveis idade e avaliação da oportunidade de treinamento. Por isso realizou-se o teste de Tukey para localizar a diferença dessas variáveis entre os quatro 
Tabela 3 Média por hotel das variáveis: idade, escolaridade, salário, avaliação da oportunidade de treinamento e expectativa.

\begin{tabular}{|c|c|c|c|c|c|c|}
\hline HOTÉIS & $\mathbf{N}$ & Idade & Escolaridade & Salário & Expectativa & $\begin{array}{c}\text { Avaliação de } \\
\text { treinamento }\end{array}$ \\
\hline A & 40 & 35,46 & 3,02 & 456,59 & 3,92 & 15,64 \\
\hline B & 25 & 32,83 & 2,50 & 484,91 & 3,86 & 13,15 \\
\hline C & 30 & 31,63 & 2,60 & 478,15 & 3,86 & 14,92 \\
\hline D & 121 & 29,46 & 2,89 & 537,37 & 3,88 & 17,46 \\
\hline Total & 216 & 31,43 & 2,83 & 508,70 & 3,88 & 16,35 \\
\hline
\end{tabular}

Fonte: Dados da pesquisa.

Tabela 4 Anova - Comparação das médias das variáveis pessoais e profissionais entre os hotéis.

\begin{tabular}{|c|c|c|r|c|c|c|}
\hline & & $\begin{array}{c}\text { Somatória dos } \\
\text { quadrados - SS }\end{array}$ & GI & $\begin{array}{c}\text { Média ao } \\
\text { quadrado-MS }\end{array}$ & F & Sig. \\
\hline Idade & Entre os grupos & 902,49 & 3 & 300,83 & 5,83 & $\mathbf{0 , 0 0 1}^{*}$ \\
\hline & $\begin{array}{c}\text { Dentro dos } \\
\text { grupos }\end{array}$ & 8665,66 & 168 & 51,58 & & \\
\hline & Total & 9568,16 & 171 & & & \\
\hline Escolaridade & Entre os grupos & 6,28 & 3 & 2,09 & 0,97 & 0,405 \\
\hline & $\begin{array}{c}\text { Dentro dos } \\
\text { grupos }\end{array}$ & 448,96 & 209 & 2,14 & & \\
\hline & Total & 455,24 & 212 & & & \\
\hline Salário & Entre os grupos & 231479,09 & 3 & 77159,69 & 0,72 & 0,537 \\
\hline & $\begin{array}{c}\text { Dentro dos } \\
\text { grupos }\end{array}$ & 20784998,91 & 196 & 106045,91 & & \\
\hline Expectativa & Total & 21016478 & 199 & & & \\
\hline Avtre os grupos & 0,07 & 3 & 0,02 & 0,03 & 0,992 \\
\hline Treinamentiaca & $\begin{array}{c}\text { Dentro dos } \\
\text { grupos }\end{array}$ & 167,23 & 210 & 0,79 & & \\
\hline & Total & 167,30 & 213 & & & \\
\hline & Entre os grupos & 411,97 & 3 & 137,32 & 10,84 & $\mathbf{0 , 0 0 0 *}$ \\
\hline & $\begin{array}{c}\text { Dentro dos } \\
\text { grupos }\end{array}$ & 2380,22 & 188 & 12,66 & & \\
\hline & Total & 2792,20 & 191 & & & \\
\hline
\end{tabular}

* Significativo com $p<0,05$

Fonte: Dados da pesquisa hotéis. Verificou-se que a diferença de idade está apenas do A para o D, sendo o primeiro possuindo uma média maior de idade $(35,46)$. Em relação à avaliação do treinamento como oportunidade de treinamento, verifica-se que o hotel D apresenta uma diferença significativa em termos de média em relação aos demais hotéis.

\section{Análise de correlação}

A correlação bivariada utilizada para as escalas de comprometimento organizacional e dados biográficos-profissionais mostrou que alguns destes últimos exercem influência nas dimensōes do construto em foco. Isso permite afirmar que há uma relação linear entre as variáveis analisadas. Na Tabela 5 tem-se a comprovação por meio dos coeficientes de Pearson.

Tabela 5 Coeficientes de correlação das variáveis biográficas e profissionais com as três dimensões do comprometimento.

\begin{tabular}{|l|c|c|c|}
\hline & NORMATIVA & INSTRUMENTAL & AFETIVA \\
\hline Idade & $0,238^{* *}$ & $0,151^{*}$ & 0,10 \\
\hline Escolaridade & $-0,196^{* *}$ & $-0,162^{*}$ & 0,10 \\
\hline Salário & 0,045 & $-0,083$ & $0,234^{* *}$ \\
\hline $\begin{array}{l}\text { Nivel das expectativas } \\
\text { atendidas }\end{array}$ & $0,211^{* *}$ & $0,165^{*}$ & $0,273^{* *}$ \\
\hline $\begin{array}{l}\text { Avaliação da oportunidade } \\
\text { de treinamento }\end{array}$ & $0,257^{* *}$ & 0,065 & $0,375^{* *}$ \\
\hline
\end{tabular}

*Correlaçâo é significativa ao nivel de 0,05. * * Correlaçāo é significativa ao nivel de 0,01.

Fonte: Dados da pesquisa

Os resultados apontam que a dimensão afetiva do vínculo apresentou uma relação de linearidade direta com as variáveis: salário $(0,234)$, nível das expectativas atendidas nos primeiros meses de trabalho $(0,273)$ e avaliação da oportunidade de treinamento como oportunidade de desenvolvimento (0,375). A dimensão normativa apresentou uma relação de linearidade com as variáveis: idade $(0,238)$, nível das expectativas atendidas nos primeiros meses de trabalho $(0,211)$, avalia- 
ção da oportunidade de treinamento como oportunidade de desenvolvimento $(0,257)$ e a escolaridade que se relacionou inversamente $(-0,196)$. A dimensão instrumental não apresentou nenhuma relação de linearidade com as variáveis. Era de se esperar uma relação entre a variável salário e a dimensão instrumental, porém isto não ocorreu, ocorrendo apenas uma correlação em sentido contrário. Tal resultado vem corroborar com os estudos de Mathieu e Zajac (1990: 179), que apontam o comprometimento puramente instrumental para uma relação negativa com a variável salário, enquanto os comprometimentos com predomínio afetivo e normativo, que não estão associados a componentes instrumentais, estão relacionados positivamente ao salário.

O trabalho de Bandeira (1999) comprova a relação significativa direta da oferta de treinamento como oportunidade de desenvolvimento com a dimensão afetiva e normativa do vínculo. $O$ fato de a empresa reconhecer a necessidade de qualificar os funcionários e investir no seu desenvolvimento profissional, em função da carência do setor por mão-de-obra qualificada, gera no indivíduo um sentimento de lealdade e afetividade para com a empresa, favorecendo sua permanência e engajamento com as ações da empresa.

Para a análise dos níveis das dimensões do comprometimento organizacional na amostra em relação às variáveis pessoais e profissionais foram utilizados o teste T de Student e a análise de variância F Snedecor, teste de hipótese utilizado para a comparação das médias, adequado para a aplicação quando mais de duas médias estão sendo comparadas.

Os resultados da Tabela 6 mostram os níveis de comprometimento por sexo.

Tabela 6 Média das três dimensões do comprometimento por sexo e o resultado do teste $\mathrm{T}$.

\begin{tabular}{|l|c|c|c|c|}
\hline & \multicolumn{2}{|c|}{ Média } & \multicolumn{2}{c|}{$\begin{array}{c}\text { Igualdade de variância } \\
\text { não assumida }\end{array}$} \\
\hline & Masculino & Feminino & T & Sig. (2-tailed) \\
\hline CNOR & 3,94 & 3,89 & 0,50 & 0,61 \\
CINS & 3,43 & 3,71 & $-2,12$ & $0,03^{*}$ \\
CAFT & 3,78 & 3,52 & 1,59 & 0,11 \\
Total & $\mathbf{1 2 9}$ & $\mathbf{8 7}$ & & \\
\hline Total & $\mathbf{1 2 9}$ & $\mathbf{8 7}$ & & \\
\hline
\end{tabular}

*Significativo a $p<0,05$

Fonte: Dados da pesquisa.
Os resultados na Tabela 6 demonstram existir diferenças significativas em relação ao sexo para o comprometimento instrumental - CINS $(t=-2,122$ e $\mathrm{p}<0,05)$. Verifica-se, assim, que as mulheres demonstram ser mais comprometidas instrumentalmente que os homens. Para os demais tipos de comprometimento não se pode afirmar que exista diferença de níveis entre os sexos.

Aplicou-se a análise de variância - One way Anova - para testar as diferenças das médias em relação aos grupos de casados, solteiros e sozinhos (viúvos e desquitados/divorciados). Os resultados estão expostos na Tabela 7.

Tabela 7 Anova - Comparação das médias dos comprometimentos em relação ao estado civil dos pesquisados.

\begin{tabular}{|l|l|c|c|c|c|c|}
\hline & & $\begin{array}{c}\text { Somatória } \\
\text { dos quadrados } \\
\text { SS }\end{array}$ & GI & $\begin{array}{c}\text { Média ao } \\
\text { quadrado } \\
\text { MS }\end{array}$ & F & Sig \\
\hline \multirow{2}{*}{ CNOR } & Entre grupos & $\begin{array}{c}0,25 \\
108,92\end{array}$ & $\begin{array}{c}2 \\
204\end{array}$ & $\begin{array}{c}0,12 \\
0,53\end{array}$ & 0,23 & 0,79 \\
& Dentro dos grupos & $\mathbf{1 0 9 , 1 7}$ & $\mathbf{2 0 6}$ & & & \\
& Total & 2,63 & 2 & 1,31 & 1,47 & 0,23 \\
\hline \multirow{2}{*}{ CINS } & Entre grupos & 182,74 & 204 & 0,89 & & \\
& Dentro dos grupos & $\mathbf{1 8 5 , 3 7}$ & $\mathbf{2 0 6}$ & & & \\
& Total & 11,08 & 2 & 5,54 & 4,36 & $0,01^{*}$ \\
\hline \multirow{2}{*}{ CAFT } & Entre grupos & 259,46 & 204 & 1,27 & & \\
& Dentro dos grupos & $\mathbf{2 7 0 , 5 4}$ & $\mathbf{2 0 6}$ & & & \\
& Total & & & & &
\end{tabular}

* Significativo com $p<0,05$

Fonte: Dados da pesquisa.

Verifica-se que há diferença de nível de comprometimento para cada grupo apenas para o comprometimento afetivo - CAFT, com F de Snedecor igual a 4,36 e nível de significância menor que 0,05 . Utilizou-se o teste de Tukey para localizar entre quais grupos (casados, solteiros ou sozinhos) se encontrava a diferença. A diferença no nível de comprometimento afetivo encontra-se entre o grupo de sujeitos casados e o grupo de sujeitos sozinhos.

Assim, as diferenças entre as médias das dimensões do comprometimento, no caso da população pesquisada, são afetadas pelo sexo, sendo as mulheres mais comprometidas instrumentalmente; pelo estado civil, em que o grupo de sujeitos casados apresenta um maior comprometimento afetivo que o grupo de sujeitos sozinhos, formado pelos viúvos e separados. Além disso, o comprometimento 
normativo está correlacionado diretamente à idade e inversamente ao nível de escolaridade. As variáveis, a avaliação do treinamento como oportunidade de desenvolvimento, as expectativas atendidas nos primeiros meses de trabalho e o salário apresentaram maiores correlações com o comprometimento afetivo. Nas demais variáveis: experiência no mesmo ramo, exercício de outra atividade, atividade mais importante na vida e socialização formal, não foram encontradas diferenças significativas nos níveis de comprometimento instrumental, afetivo ou normativo.

Em relação aos hotéis, todos apresentam o mesmo nível de comprometimento normativo e instrumental. Apenas em relação à dimensão afetiva o hotel D se destaca em relação ao hotel C, apresentando maior nível. Esta diferença devese à percepção dos funcionários sobre os treinamentos oferecidos pela empresa, pois avaliam-nos não só como um recurso para capacitá-los para o desempenho de mais uma tarefa, mas também para o desenvolvimento profissional. Em relação às variáveis pessoais/profissionais não há diferença significativa entre os hotéis.

\section{Conclusões e Recomendações}

Este estudo procurou mensurar o nível do comprometimento organizacional e a relação entre as variáveis biográficas e profissionais com o construto estudado, nos empregados de alguns hotéis da cidade de Uberlândia.

Diante dos resultados, vê-se a predominância da dimensão normativa do vínculo, na amostra. Em relação aos hotéis, o hotel D se destaca do hotel $\mathrm{C}$ em relação à dimensão afetiva do vínculo.

Retomando os estudos de Meyer e Allen (1991), tem-se:

- empregados com um forte comprometimento afetivo exercem um esforço considerável em prol da organização porque gostam;

- empregados com um forte comprometimento instrumental fazem porque precisam, não têm outra alternativa;

- empregados com um forte comprometimento normativo fazem porque eles sentem que são obrigados.

Assim, na indústria hoteleira, onde acolhimento interfere significativamente no fluxo de turistas (AVENA, 2001), torna-se importante saber administrar o comprometimento dos funcionários, sobretudo favorecendo o predomínio das dimensões afetivas e normativas do vínculo indivíduo-organização. A dimensão afetiva deve estar presente em níveis moderados para proporcionar a esponta- neidade nas ações, a atitude positiva. $O$ indivíduo faz ou age daquela forma porque gosta, sente prazer em fazer, em servir. Por outro lado, a dimensão normativa irá sustentar o vínculo afetivo, no momento em que são amparados pelas regras, normas e procedimentos estabelecidos pela empresa.

Sabe-se, a partir deste trabalho, que na hotelaria, o favorecimento de treinamentos que promovam o desenvolvimento do funcionário, bem como os atendimentos das expectativas nos primeiros meses de trabalho propiciam o engajamento afetivo e normativo do vínculo. Aliado a isso, a idade e a remuneração justa contribuem para o desenvolvimento respectivamente das dimensões normativas e afetivas do comprometimento.

Investigar comprometimento organizacional na hotelaria amplia o campo de investigação e contribui de forma significativa para um setor tão importante, porém esquecido no campo do comportamento organizacional. Como sugestão para futuras pesquisas faz-se necessário identificar os padrões de comprometimento organizacional. Seria, também, importante que se reformulasse o instrumento validado por Medeiros (1997), pois consta de muitas questões invertidas, o que, para o público de nossas empresas, a maioria com ensiṇo médio incompleto, torna difícil o entendimento.

Deve ser lembrado aqui que nenhuma investigação se encontra concluída em termos definitivos. É necessário dar continuidade a esta linha de pesquisa e atualizar constantemente os conhecimentos neste campo, visando obter maior satisfação no trabalho por parte dos funcionários e maior eficácia na prestação de serviços pelo setor de hotelaria.

\section{Referências Bibliográficas}

ABIH. 2002. Hotéis e hóspedes do novo milênio. Disponível em <http://www.abih.com.br/ historia/ historia_hotl_hosp.htm>,p.1-2. Acesso em 08 jan. 2002.

AVENA, B.M. 2001. Acolhimento de qualidade: fator diferenciador para o incremento do turismo. Turismo em Análise, São Paulo: ECA-USP, v.12, no 1, p. 20-29, maio.

BANDEIRA, M. L.; MARQUES, A. L.; VEIGA, R. T. 1999. A ECT na trilha da modernidade: políticas de recursos humanos influenciando múltiplos comprometimentos. In: ENCONTRO ANUAL ANPAD, 23, Foz do Iguaçu. CD-ROM.

BASTOS, A.V. B. 1994. Comprometimento no trabalho: a estrutura dos vínculos do trabalhador com a organização, a carreira e o sindicato. 294 f. Tese (Doutorado em Psicologia) - Programa de Pós-graduação em Psicologia, UNB, Brasília.

BASTOS, A. V. B; ROCHA, A. S de C. 1999. Comprometimento do empregado e contextos organizacionais em mudança: o caso do Banco do Brasil. In: ENCONTRO ANUAL ANPAD, 23, Foz do Iguaçu. CD-ROM. 
BECKER, H.S. 1960. Notes on the concept of commitment. The American Journal of Sociology, Chicago, v.66, nํำ 1, p. 32-40.

BROWN, S A. 1992. Total quality service: how organizations use it to create a competitive advantage. Ontário: Prentice-Hall.

CLUGSTON, M. 2000. Does cultural socialization predict multiple bases and foci of commitment? Journal of Management, Jan.

ETZIONE, A. 1975. Análise comparativa de organizaçōes complexas: sobre o poder, o engajamento e seus correlatos. Rio de Janeiro: Zahar.

HREBINIAK, L. G.; ALLUTO, J. A. 1972. Personal and role-related factors in the development of organizational commitment. Administrative Science Quarterly, v.17, p. 555-573.

MATHIEU, J. E.; ZAJAC, D. M. 1990. A review and meta-analysis of the antecedents, correlates and consequences of organizational commitment. Psychological Bulletin, v.108, p. 177 e 179.

McGEE, G. W., FORD, R. C. 1987. Two (or more?) dimensions of organizational commitment: reexamination of the affective and commitment scales. Journal of Applied Psychology, v.72, p. 638-642.

MEDEIROS, C. A. 1997. Comprometimento organizacional, características pessoais e performance no trabalho: um estudo dos padrōes de comprometimento organizacional. $111 \mathrm{f}$. Dissertação (Mestrado em Administração) - Programa de Pós-graduação em Administração, UFRN, Natal. MEYER, J. P.; ALLEN, N. J. 1991. A three-component conceptualization of organizational commitment. Human Resource Management Review, v. 1, p.61-89. 1997. Commitment in the workplace: theory, research, and application. London: Sage Publications.

; SMITH, C. A. 1993. Commitment to organizations and occupations: extension and test of a three-component conceptualization. Journal of Applied Psychology, v.78, n 4, p.538-551.

MOLLER, C. 1997. O lado humano da qualidade: maximizando a qualidade de produtos e serviços através do desenvolvimento das pessoas. São Paulo: Pioneira.

MOWDAY, R. T.; PORTER, L. W.; STEERS, R. M. 1982. Employee organizational linkages: the psychology of commitment, absenteeism and turnover. New York: Academic Press.

RANDALL, D. 1987. Commitment and the organization: the organization man revisited. Academy of Management Review, v.12, nº 3, p. 460-471.

RITZER, G.; TRICE, H. M. 1969. An empirical study of Howard Becker's side-bet theory. Social Forces, v. 47, p. 475-479.

WEINER, Y. 1982. Commitment in organizations: a normative view. Academy Management Review, v. 7, p. 418- 428.

:VARDI, Y. 1990. Relationships between job, organization, and career commitment and work outcomes - an integrate approach organizational behavior. Human Performance, 26, p. 81- 96.

Recebido em 06/11/2002

Aprovado em 11/12/2002 